\title{
АНАЛИЗ ПРОГРАММ ПОСТКОВИДНОЙ РЕАБИЛИТАЦИИ: ПРОБЛЕМЫ И ВЕКТОРЫ РАЗВИТИЯ
}

\section{ANALYSIS OF POST-OVARIAN REHABILITATION PROGRAMS: PROBLEMS AND VECTORS OF DEVELOPMENT}

M. Sidorchuk

Summary. The article analyzes the rehabilitation programs during the postcoid recovery period. The need to transform health care in an emergency of the coronavirus pandemic towards strengthening the rehabilitation component is considered, which will preserve the physical, mental health and social well-being of patients who have undergone COVID-19.

Keywords: comprehensive rehabilitation, COVID-19 epidemic, mental health, online technology.
Сидорчук Мария Александровна

Медсестра реабилитационного медицинского центра, Первый Московский государственный медицинский университет им. И. М. Сеченова maria_M.98@mail.ru

Аннотация. В статье анализируются программы реабилитации в период постковидного восстановления. Рассматривается необходимость трансформации здравоохранения в условиях чрезвычайной ситуации пандемии коронавируса в сторону усиления реабилитационной составляющей, что позволит сохранить физическое, психическое здоровье и социальное благополучие пациентов, перенесших COVID-19.

Ключевые слова: комплексная реабилитация, эпидемия COVID-19, психическое здоровье, онлайн-технологии.

связано также с финансовыми проблемами и психологической устойчивостью пациента к длительному лечению. Так, например, почти у всех выживших ранее в ОИТ «наблюдается снижение повседневной активности через год после выписки, средняя распространенность клинически важных симптомов тревоги и депрессии составляет $24 \%$ и $28 \%$ соответственно, а у одной трети пациентов симптомы посттравматического стрессового расстройства развиваются в первые 2 года после тяжелого заболевания» (2).

Сегодня можно говорить о стационарной и домашней постковидной реабилитации. Классические программы пульмонологической реабилитации «базируются на трех китах: дозированная физическая нагрузка, аппаратная физиотерапия и методы респираторной реабилитации» (7).

\section{Стационарная реабилитация}

Восстановление функции органов после перенесенного COVID-19 возможно в короткие сроки только при комплексном подходе к реабилитации. Это позволяет пациентам вернутся к привычному образу жизни уже через две недели после интенсивного курса восстановления и предотвратить повторное инфицирование.

Сегодня в РФ при крупных региональных больницах и реабилитационных центрах РФ были разработаны и внедрены программы, ориентированные на катего- 
рию пациентов, перенесших инфицирование COVID-19 с целью восстановления иммунного ответа для снижения рисков реинфицирования. «Мультидисциплинарная команда (неврологи, кардиологи, терапевты, реаниматологи, урологи) разрабатывает индивидуальный план реабилитационной программы, в которую входит комплекс процедур: лечебная гимнастика, дыхательная гимнастика с применением респираторных тренажеров, массаж, психо- и диетотерапия, физиотерапия, включая ингаляции, электро- и магнитотерапию, вибротерапию, гипербарическую оксигенацию, рефлексотерапию, логотерапию и т.д.» (9). Такая программа способствует восстановлению функции легких, работы сердечно-сосудистой системы, воздействие на органы чувств (восстановление обоняния), а также снижение рисков декомпенсации хронических заболеваний и реабилитацию психоэмоциональной и когнитивной сферы для полного восстановления органов.

Специалисты пытаются начать реабилитацию как можно раньше, даже когда пациент находится на искусственной вентиляции легких. Возможные препятствия на пути к реабилитации тяжелобольных пациентов это привязанность к различным медицинским устройствам с помощью проводов и трубок, что затрудняет мобилизацию и особенно передвижение. Обученный персонал и вспомогательное оборудование могут повысить безопасность и эффективность передвижения тяжелобольных пациентов. Например, в МИКУ Джонса Хопкинса и в других местах, чтобы упростить передвижение пациента и сократить потребность в персонале, использовалось средство передвижения, которое объединяет все необходимое оборудование в одно портативное устройство (мониторы сердечного ритма и сатурации кислорода, стандартный вентилятор с батарейным питанием, переносной вентилятор) (2). Сейчас в арсенале реабилитологов имеется большое количество разнообразного оборудования для ранней реабилитации прикроватные тренажеры мотомеды, вертикализаторы для постепенного перевода тяжелого пациента из лежачего положения в вертикальное, аппаратная физиотерапия для стимуляции дыхательных мышц и диафрагмы для ускорения перевода с ИВЛ на собственное дыхание.

После окончания реабилитационной программы пациент и его семья должны получить подробные рекомендации для продолжения реабилитационных мероприятий дома. Сроки стационарной реабилитации пациентов, перенёсших заболевание средней и тяжёлой степени с развитием дыхательной недостаточности, рекомендуется продолжительностью от 4 до 8 недель. Если пациент перенёс пневмонию в лёгкой форме, то при положительной динамике пациенту могут рекомендовать прохождение дистанционной реабилитации. По данным факультета интенсивной терапии FICM британской про- фессиональной медицинской организации, занимающейся обучением врачей-реаниматологов, пациенты с тяжелой формой болезни могут получить столь сильные повреждения легких, что на восстановление им понадобится более 10 лет.

К положительным результатам, которых пациент может достичь после ранней стационарной реабилитации в отделении интенсивной терапии, можно отнести: уменьшение одышки, увеличение показателя дыхательного легочного объема; повышение толерантности к физическим нагрузкам, улучшение психоэмоционального состояния; быстрое возвращение к привычной жизни и работе, снижение рисков возникновения хронических легочных болезней. Кроме того, программы ранней реабилитации могут быть связаны с сокращением продолжительности пребывания в стационаре и ОИТ, продолжительностью искусственной вентиляции легких и больничными расходами (2).

Основным препятствием является повсеместное отсутствие мультидисциплинарного персонала, междисциплинарного сотрудничества, недостатка знаний о еще не совсем изученной новой вирусной инфекции (2).

Потенциальным препятствием на пути к успешной реализации программ ранней реабилитации, особенно в регионах, является почти полное отсутствие государственных постковидных реабилитационных отделений в регионах и вариативность финансирования по регионам РФ. В регионах пропорционально удалению от центра наблюдается финансовая несостоятельность большинства пациентов. Даже за границей в зависимости от вариативности финансирования в большинстве регионов США медсестра просто ограничивается одноразовым наблюдением по телефону, и только «в пяти особо острых региональных стационарных специализированных реабилитационных отделениях пациентов принимают непосредственно из отделения интенсивной терапии, а некоторые индивидуальные фонды разработали отличные услуги для ранней амбулаторной реабилитации после ОИТ» (1).

Важнейшей составляющей комплексной постковидной реабилитации является психологическое вмешательство в раннем отделении интенсивной терапии. Например, предварительное исследование пациентов в Италии, поступивших в травматологическое отделение интенсивной терапии, оценило результаты психического здоровья через 12 месяцев после психологического вмешательства по сравнению с обычной помощью без участия психолога. В задачу психолога входило обучение адаптивным навыкам совладания с ситуацией, консультирование, управление стрессом, психологическую поддержку и стратегии выживания, а также навыки пре- 
одоления после выписки. Через 12 месяцев после выписки из ОИТ симптомами посттравматического стрессового расстройства снизились с $57 \%$ до $21 \%$, уровень тревожности с $17 \%$ до 9\%, депрессия с 13\% до 7\% (2).

Таким образом, ранние реабилитационные вмешательства могут уменьшить осложнения соматического и психического здоровья, часто возникающие у выживших после критического заболевания. «Потенциальные преимущества, связанные с ранней физической и психической реабилитацией безопасны и осуществимы, если они проводятся в рамках мультидисциплинарного командного подхода. Дневники реанимации, наряду с другими психологическими вмешательствами в отделениях интенсивной терапии и амбулаторно, заслуживают рассмотрения как средства снижения бремени психических осложнений после тяжелой болезни» (2). Уже сейчас правительство Великобритании прогнозирует, что 45\% пациентов ковидных отделений будут нуждаться в какой-либо форме медицинского или социального вмешательства на легком уровне для выздоровления, а 4\% потребуют более целенаправленной, постоянной интенсивной реабилитации в постели. Английские консультанты по реабилитационной медицине считают, что «нам нужны все эти разные уровни обслуживания. И, что важно, нам нужно, чтобы они были объединены» (1).

\section{Аомашняя реабилиташия}

Сертифицированное общество физиотерапии обеспокоено тем, что будет, когда люди пойдут домой, что это будет «проблема вне поля зрения» (1). Даже при строгом соблюдении всех правил лечения в остром периоде коронавируса можно получить нежелаемый результат. И это очень сильно зависит теперь от эффективности постковидной реабилитации, при этом надо учитывать индивидуальные особенности пациента (пол, возраст, степень поражения органов, тяжесть сопутствующих заболеваний, уровень психологической устойчивости пациента), т.е. нужно говорить об индивидуальной постковидной реабилитации. При этом надо учитывать возможные дальние мишени: сильную усталость, перепады настроения, боли в мышцах и суставах, головные боли и туман в мозгу, когнитивные нарушения.

Те, кто восстанавливается в домашних условиях, сталкиваются с рядом организационных и психологических проблем на всех уровнях.

1. Недостаточный уровень информированности по реабилитации COVID-19. Все памятки по COVID-19 касаются в основном профилактики, диагностики и лечения новой коронавирусной инфекции, но нет памяток для широких слоев населения по реабилитации после перенесенного заболевания, и пациенты оказываются после лечения «в пустоте». В первую очередь после лечения необходимо информационное сопровождение пациента, т.к. он не имеет представления, находясь в стрессовой ситуации, а что он должен делать дома дальше. Поэтому каждому пациенту, независимо от того, где он лечился, в стационаре либо в поликлинике, надо выдавать распечатанную брошюру-памятку с указанием информации по блокам: физическому, психологическому, когнитивному, социально-бытовому с рекомендациями по каждому из блоков с указанием сайтов и онлайн-адресов дистанционных консультаций по каждому из блоков. Это в первую очередь касается регионов, в которых в условиях разворачивающейся эпидемии коронавируса попасть очно на консультацию к кардиологу, пульмонологу и другим узким специалистам очень сложно, а также это касается пожилых людей, не владеющих цифровой грамотностью.

Очень своевременными оказались «Рекомендации для поддержки самостоятельной реабилитации после болезни, вызванной COVID-19», выпущенные Европейским региональным бюро ВОЗ и помещенные на сайте.

2. Сегодня реабилитация после сердечного приступа, травмы или инсульта имеет хорошо налаженные пути. А реабилитационных постковидных центров во многих регионах России почти нет и вообще нет реабилитационных отделений по когнитивной реабилитации, хотя многие врачи-неврологи и эксперты отмечают у пациентов, перенесших COVID-19, такие когнитивные нарушения, как жалобы на слабость, снижение концентрации внимания, повышенную утомляемость, нарушение координации и ориентирования во времени и пространстве. По наблюдениям врачей около $50 \%$ времени реабилитации пациентов, перенесших ковидную инфекцию, уходит на тренировку когнитивных функций, внимания, концентрации.

Таким образом, помочь в реабилитации пациентов с когнитивными нарушениями могут практики, которые обычно применяются в неврологии, позволяющие корректировать факторы риска и реабилитация после состояний, связанных с гипоксией. Для борьбы с такими последствиями коронавируса необходимо избегать стресса, принимать витаминные и минеральные комплексы с повышенным содержанием витаминов группы В, магния и цинка. Есть специальные противоастенические препараты, рассчитанные на неврозоподобные состояния.

3. Сегодня отсутствует необходимая психологическая поддержка, ведь пациенты с COVID-19 будут нуждаться в даже большей психологической поддержке, чем обычные пациенты интенсивной терапии, из-за более высо- 
кого уровня «вины выживших» и посттравматического стрессового расстройства.

Сегодня создан и успешно действует сайт «Стопкоронавирус. РФ», в котором есть рубрика «Психологический Антивирус. Все будет хорошо».

Заразиться новым коронавирусом (COVID-19) могут представители всех возрастных категорий и социальных слоев. Исследования выявили влияние на психологическое благополучие наиболее подверженных воздействию групп, включая детей, студентов, медицинских работников, пожилых, у которых с большей вероятностью разовьется посттравматическое стрессовое расстройство, тревога, депрессия и другие симптомы дистресса.

К психологическим проблемам многих российских студентов следует отнести нестабильное психологическое состояние и их эмоциональную неустойчивость вообще в экстремальных ситуациях. На это повлияло резкое сужение коммуникации и живого общения с друзьями и ближайшими родственниками, потеря свободы, неуверенность в развитии болезни и чувство беспомощности. У многих студентов разных профессий повысился уровень тревожности и агрессии. Эти аспекты могут привести к драматическим последствиям, таким как рост самоубийств (5).

Сегодня доказано также более сильная эмоциональная неустойчивость, ковидофобия именно у молодого поколения по сравнению с пожилыми людьми. Предполагается, что это «связано с технологической природой современного молодого поколения. Это делает их более подверженными влиянию и стрессу из-за доступа к неограниченной, но непроверенной информации, доступной в Интернете и на платформах социальных сетей» (3). Психологическая служба, работающая дистанционно, должна помочь конструктивно проживать негативные эмоции, правильно оценивать ситуацию, научить позитивно смотреть на сложившуюся ситуацию, помочь себя организовать и распланировать свое время (8). Для них будут полезны онлайн-когнитивно-поведенческая терапия и терапия на основе осознанности (3).

У медработников также есть риск развития посттравматического стрессового расстройства, синдром выгорания, физическое и эмоциональное истощение, деперсонализация и диссоциация (5). При этом, степень выгорания сильно зависит от возраста, рода занятий, время нахождения дома, часов работы, сопутствующих психологических заболеваний, контакта с пациентами с COVID-19, страх заражения, поддержка семьи и поддержка друзей.

Например, в Италии уровень эмоционального истощения от умеренного до тяжелого и снижение личных достижений присутствовали более чем в 60\% выборки. У медработников наблюдался высокий процент депрессии (50\%), беспокойства (44,6\%), бессонницы (34\%) и дистресса (71,5\%). Кроме того, постоянный страх заражения приводит к навязчивым мыслям, увеличивая прогрессивное закрытие личности и сокращая социальные отношения» (5). Неопытным работникам следует сотрудничать с более опытными коллегами. Такие «приятельские» системы помогают оказывать поддержку, контролировать стресс и укреплять процедуры безопасности. Эффективность вмешательства со стороны сверстников зависит от духа товарищества и чувства общей судьбы, которые могут возникнуть из общего опыта травмы.

Все это в итоге может снизить способность систем здравоохранения справляться с повышенным спросом на помощь, которая может возникнуть как в краткосрочной, так и в долгосрочной перспективе. Все это требует переосмысления своих ценностей, изменения отношения к себе, своему окружению, окружающему миру. И каждый делает индивидуальный выбор в отношении своего здоровья и здоровья окружающих.

\section{ИсслеАование уровня гражАанской ответственностИ стУАентов \\ по профилактике и реабилиташии \\ инфекционных заболеваний}

\section{Цель исследования}

Проследить динамику поведенческих подходов студентов по профилактике и реабилитации инфекционных заболеваний в пандемию коронавируса, а также оценить их гражданский потенциал в чрезвычайной ситуации.

Для выявления такого уровня в условиях пандемии были использованы анкетирование и метод контент-анализа психологических эссе студентов разных вузов из разных регионов. Исследование проводилось дистанционно посредством социальных сетей. Количество респондентов-50 студентов Московского медицинского вуза (Сеченовского университета), 50 студентов Московского технического вуза (МГТУ Станкин) и 50 студентов Смоленского государственного университета (СмолГУ).

Анализ результатов уровня гражданской ответственности показал широкий разброс ответов в зависимости от региона и будущей профессии.

Необходимость ограничительных мероприятий при существующей реальной угрозе высказали только 65\% студентов технического университета, 85\% медиков и $90 \%$ смолян. 
На вопрос «Ваше отношение к санитарно-гигиеническим мероприятиям?» 70\% студентов-медиков, 86\% студентов технического университета, 65\% смоленских студентов-гуманитариев ответили «необходимы и излишни». Боятся заболеть COVID-19?» только 40\% студентов технического университета, 20\% медиков и 58\% смолян, что косвенно говорит о более высоком уровне ковидофобии и более низком уровне эмоциональной устойчивости у смолян. Причем привиться от коронавируса после завершения регистрации вакцины больше всех пожелали именно студенты смоленского вуза.

На следующий вопрос «Устали ли вы от проводимых ограничительных мероприятий во время пандемии? 90\% всех студентов во всех регионах ответили положительно. Современному уровню диагностики тестирования на COVID-19 доверяют только 60\% молодых людей всех вузов.

Ухудшение физического состояния в связи с эпидемией коронавируса связывают 15\% студенты технического университета, 30\% студентов-гуманитариев, 50\% студентов-медиков, т.к. были закрыты спортзалы, парки, детские площадки, центры активного отдыха.

На вопрос «Ухудшилось ли ваше психическое состояние и связываете ли вы это с эпидемией коронавируса?» 40\% студентов техуниверситета, 90\% студентов-медиков, 70\% студентов-смолян ответили положительно. Для улучшения своего настроения все они независимо от региона применяют следующее: «гуляю, рисую, ем, совершаю необдуманные покупки, читаю, смотрю кино, общаюсь с друзьями, занимаюсь рукоделием, спиртное, не смотрю новости».

Ранжирование необходимых видов реабилитации после лечения ковид-инфекции все студенты отметили так: в первую очередь, медицинская, затем психологическая, профессиональная, правовая, когнитивная, социально-бытовая, просветительская.

На вопрос «Как изменилось Ваше качество жизни в последние полгода и чего Вам стало больше всего не хватать?» большинство студентов отметили, что их жизнь особенно не изменилась, но им не хватает «живого общения, полноценного отдыха, посещения культурно-досуговых мероприятий без боязни заразиться, путешествий, моря, ресторанов, прогулок на свежем воздухе».

Уровень подготовки российского Минздрава к эпидемии COVID-19 по 5-бальной системе студенты оценили так: студенты московского технического университета на 5 баллов-0\%, на 4 балла-15\%, на 3 балла-60\%, на 2 балла- $25 \%$, студенты московского медицинского универси- тета на 5 баллов-0\%, на 4 балла -60\%, на 3 балла-40\%, студенты-смоляне на 3 балла-30\%, на 2 балла-70\%.

Несмотря на разные ответы, 80\% всех студентов отметили увеличение уровня индивидуальной гражданской ответственности за время эпидемии коронавируса.

Таким образом, результаты исследования показали, что большинство студентов российских вузов отмечают ухудшение психического здоровья, увеличение индивидуальной гражданской ответственности, хотя и по разным причинам (болезнь и смерть родственников и знакомых, чувство долга, моральные принципы, ковидофобия, боязнь больших штрафов и т.д.). Причем этот уровень постепенно повышался от первой ко второй волне коронавирусной инфекции. Мы также видим, что, независимо от профессиональной направленности и региона проживания студентов, необходимо все-таки усилить их морально-нравственное и гражданско-патриотическое воспитание, отвечающие за уровень гражданской ответственности, что позволит сохранить в итоге физическое и психическое здоровье молодого поколения.

\section{Векторы развития}

1. К основным рекомендациям по сохранению психического здоровья Глобальная комиссии по психическому здоровью отнесла использование телемедицины и цифровых технологий, которые могут обеспечить вмешательство в психическое здоровье, чтобы снизить уровень тревожности и стресса (5).

Для психологической поддержки молодого поколения надо применять новые онлайн-технологии, например, онлайн-общение со своими кумирами, привлечение знаменитостей к психподдержке населения, онлайн-трансляции, международные онлайн-концерты, на которых в том числе затрагиваются вопросы коронавируса.

Телепсихология и технологические устройства играют важную роль в уменьшении негативных последствий пандемии. Эти инструменты предоставляют преимущества, которые могут улучшить психологическое лечение пациентов в Интернете, например возможность встречаться дома или на рабочем месте, экономия денег и времени и поддержание отношений между терапевтами и пациентами. «Развитие технологий в области психического здоровья предвещает будущие тенденции, которые включают «умные» мобильные устройства, облачные вычисления, виртуальные миры, виртуальную реальность и электронные игры в дополнение к традиционным инструментам психотерапии» (5). 
2. Развитие телепсихологии и телепсихиатрии связано с 2 крупными проблемами: подготовкой кадров телемедицины и цифровая диспансеризация населения, т.к. сегодня цифровая грамотность населения России очень низкая, а среди пожилого населения она составляет всего лишь 2-3\%. В этой связи ярким примером подготовки специалистов является Университет Содружества Вирджинии (VCU), который предложил докторскую степень в области телепсихологии с целью обучения будущих психологов управлению психологическими последствиями пандемии через онлайн-психологическую службу (5).

3. Необходимо способствовать мониторингу состояния физического и психического здоровья медицинских работников в эти кризисные моменты. Во время и после чрезвычайной ситуации можно было бы реализовать несколько стратегий для поддержки медицинских работников, работающих с пациентами с COVID-19, которые включают программы регулирования рабочего времени, снижение рабочей нагрузки на медицинских работников, реализацию стратегий по снижению давления при принятии сложных решений, планирование официальных и неофициальных вознаграждений, предоставление индивидуальных или групповых программ психологической поддержки, продвижение фокус-групп для продвижения предложений по улучшению организации работы. Внимание должно быть сосредоточено на продвижении позитивных и защитных стратегий, чтобы справиться с чрезвычайной ситуацией, разработанных при поддержке психолога. Причем исследования психологических потерь медицинских работников во время вспышек показало, что психологический стресс у них может длиться до трех лет после вспышки.

4. Сегодня созрела необходимость глобального международного научного сотрудничества во время этой пандемии, чтобы восполнить пробелы в знаниях в подходе от страны к стране.

Таким образом, сегодня нужно говорить о необходимости трансформации здравоохранения в сторону усиления реабилитационной составляющей. Мы имеем ситуацию, когда комплексная реабилитация нужна не только многим возрастным категориям, переболевшими COVID-19 и оказавшимися в трудной жизненной ситуации, но и многим не переболевшим, так как эпидемия привела к ухудшению их психического здоровья из-за стресса и ковидофобии. Необходимо использовать новейшие разработки в области реабилитации, в том числе телемедицины и цифровых технологий, усилить когнитивную реабилитацию, реформировать кадровую составляющую и провести цифровую диспансеризацию населения.

\section{ЛИТЕРАТУРА}

1. Covid-19: the challenge of patient rehabilitation after intensive care BMJ 2020; 369 doi: https://doi.org/10.1136/bmj.m1787

2. Early Rehabilitation in the Intensive Care Unit: Preventing Physical and Mental Health Impairments. https://pubmed.ncbi.nlm.nih.gov/24436844/

3. Psychological impact of mass quarantine on population during pandemics -The COVID-19 Lock-Down (COLD) study. https://doi.org/10.1371/journal.pone.0240501 October 22, 2020

4. Support for Rehabilitation Self-Management after COVID-19- Related IIIness. https://apps.who.int/iris/bitstream/handle/10665/333287/WH0-EURO-2020-85540590-54571-eng.pdf

5. The Psychological and Social Impact of Covid-19: New Perspectives of Well-Being Front. Psychol., 02 October 2020, https://doi.org/10.3389/fpsyg.2020.577684

6. Васильева Н.Г. Ученые отмечают появление нового страха — коронафобии. https://academia.interfax.ru/ru/news/articles/4582/?fbclid=lwAR3Y08gSQb7_482qlj4LiRg5q1pMC9wZowJsU-Mx6XxCIWxILiPst0c8eM

7. Гусакова Е. «Реабилитация после коронавируса необходима каждому». https://iz.ru/1085913/valeriia-nodelman/reabilitatciia-posle-koronavirusaneobkhodima-kazhdomu

8. Черникова Т.В., Болучевская В.В., Новикова Ю.Г. Технологии психопрофилактики эмоционального выгорания у студентов медицинских вузов//Профессиональный и организационный стресс: диагностика, профилактика и коррекция: материалы Всерос. науч.-практ. конф. Астрахань, 2011.

(c) Сидорчук Мария Александровна ( maria_M.98@mail.ru ).

Журнал «Современная наука: актуальные проблемы теории и практики» 